\title{
The interaction of piperylene and its chlorine derivatives with aromatic amines
}

\author{
(C) Akhat G. Mustafin, ${ }^{1,2 *}$ Vakil M. Sharafutdinov, ${ }^{3}$ Ildus B. Abdrakhmanov, ${ }^{2}$ and Yury S. Zimin ${ }^{1+}$ \\ ${ }^{1}$ Department of Physical Chemistry and Chemical Ecology. Bashkir State University. Zaki Validi St., 32. \\ Ufa, 450074. Republic of Bashkortostan.Russia.Phone: +7 (347) 229-96-94.E-mail: ZiminYuS@mail.ru \\ ${ }^{2}$ Laboratory of Pharmacophore Cyclic Systems. Ufa Institute of Chemistry - Subdivision \\ of the Ufa Federal Research Centre of the Russian Academy of Sciences. \\ Oktyabrya Pr., 71. Ufa, 450054. Republic of Bashkortostan. Russia. \\ ${ }^{3}$ Department of General Chemical Technology. Branch of Ufa State Petroleum Technological University \\ in Sterlitamak. Oktyabrya Ave., 2. Sterlitamak, 453118. Republic of Bashkortostan. Russia.
}

\begin{abstract}
*Supervising author; ${ }^{+}$Corresponding author
\end{abstract}
Keywords: aromatic amines, alkylation, piperylene, 4-chloro-2-pentene, 3,4-dichloro-2-pentene, Lewis acids, amino Claisen rearrangement.

\begin{abstract}
The article considers the possibility of introducing a pentenyl radical into the structure of aromatic amines by the interaction of the latter with piperylene and its chlorine derivatives, 4-chloro-2-pentene and 3,4dichloro-2-pentene. Direct alkenylation of aniline with piperylene in the presence of Lewis acids leads to $C$ alkenyl arylamines. The most effective catalyst is $\mathrm{AlCl}_{3}$. Along with the expected 2- and 4-(1-methyl-2butenyl) anilines, the formation of 2,4-di- and 2,4,6-tri-(1-methyl-2-butenyl) anilines is observed, the latter being virtiually the only product in the reaction with a 5-fold excess of piperylene. In addition to Lewis acids, $\mathrm{H}_{3} \mathrm{PO}_{4}$ deposited on kieselguhr or silica gel, as well as polyphosphoric acid, were used to catalyze this reaction. Under the action of these catalysts, ortho- and para-alkenylated anilines are mainly formed, and the yield of the ortho-isomer, reaching $34 \%$, always exceeds the yield of the para-product. It is possible that, under these conditions, $N$-alkenylation occurs simultaneously with direct $C$-alkenylation followed by an amino rearrangement. The yield of the 2,4-dialkenyl product does not exceed $8 \%$, and trialkenylated aniline is completely absent. The optimal reaction temperature is in the range of $180-200{ }^{\circ} \mathrm{C}$, at higher temperatures the yield of the target products decreases due to the polymerization of piperylene. Various aniline derivatives are also involved in the reaction with piperylene. When one of the ortho positions in the arylamine molecule is occupied, as in ortho-toluidine or in 2-chloroaniline, a mixture of the three products is formed in comparable amounts. The reaction of meta-toluidine with piperylene also leads to the mixture of three products, and the substitution does not affect the 2-position between the amino and methyl groups. If both ortho-positions are occupied, as in 2-methyl-6-ethylaniline, the reaction is quite successfully under way in the para-position (yield is 61\%). To increase the selectivity of the process, the alkylation of aromatic amines is best carried out not by piperylene, but by its chlorine derivatives. The reaction of aniline with 4-chloro-2-pentene takes place in the environment of triethylamine and leads to $N$-(1-methyl-2-butenyl) aniline with a yield of $80 \%$. Other primary and secondary arylamines react in the same way. The reaction with 3,4-dichloro-2-pentene proceeds under more severe conditions. If the reaction of aromatic amines with 4-chloro-2-pentene is carried out not in triethylamine medium, but in an excess of arylamine itself as a solvent, then not $N$-but $C$-substituted products are formed. The reaction proceeds as a consequitive-simultameous process. In the first stage, $N$-alkenylation occurs with the formation of $\mathrm{N}$-(1-methyl-2-butenyl) arylamine followed by an amino rearrangement of Claisen under the catalytic action of evolved $\mathrm{HCl}$. Alongside with the obvious predominance of orthosubstituted arylamine (64-82\%), para-isomers and, in some cases 5-12\% of 2,4- or 2,6-disubstituted compounds were found in the reaction products. The amino rearrangement in the interaction of arylamines with 3,4-dichloro-2-pentene proceeds with exceptional ortho-selectivity. Alkyl groups at nitrogen and ortho positions accelerate, and ortho-chloro, para-methyl, 2,4-dimethyl substituents slow down the process, while the meta-methyl group has no significant effect. The same dependence was observed in the case of 4-chloro-2pentene. Thus, pentenyl fragment can be introduced in various ways into the structure of aromatic amines: by direct interaction with piperylene in the presence of catalysts, $\mathrm{N}$-alkenylation of 4-chloro-2-pentene and 3,4dichloro-2-pentene in triethylamine medium and reaction of arylamines with chlorine derivatives of piperylene, accompanied by an amino rearrangement of Claisen.
\end{abstract}




\section{References}

[1] Yu.T. Nikolaev, A.M. Yakubson. Aniline. Moscow: Khimiya. 1984. 152p. (russian)

[2] A.G. Mustafin, I.B. Abdrakhmanov, V.M. Sharafutdinov, and Yu.S. Zimin. Synthesis of di- and trialkenylsubstituted aromatic amines. Butlerov Communications. 2018. Vol.54. No.4. P.88-93. DOI: 10.37952/ROI-jbc-01/18-54-4-88

[3] J.E. Hyre, A.R. Bader. Unsaturated aromatic amines, a novel synthesis of indoles. Journal of the American Chemical Society. 1958. Vol.80. P.437-439.

[4] A.R. Bader, R.J. Bridgwater, P.R. Freeman. Indoles. II. The acid-catalyzed rearrangement of N-2alkenylanilines. Journal of the American Chemical Society. 1961. Vol.83. P.3319-3323.

[5] L.S. Hegedus, P.M. Winton, S. Varaprath. Palladium-assisted N-alkylation of indoles: attempted application to polycyclization. Journal of Organic Chemistry. 1981. Vol.46. P.2215-2221.

[6] S.J. Danishefsky, G.B. Phillips. A rapid route to ergot precursors via aza-Claisen rearrangement. Tetrahedron Letters. 1984. Vol.25. P.3159-3162.

[7] A.G. Mustafin, I.N. Khalilov, V.M. Sharafutdinov, D.I. Dyachenko, I.B. Abdrakhmanov, G.A. Tolstikov. A modified synthesis of ellipticine. Russian Chemical Bulletin. 1997. No.3. P.630-631. (russian)

[8] J.A. Murphy, K.A. Scot, R.S. Sinclan, N. Lewis. A new synthesis of indoles. Tetrahedron Letters. 1997. Vol.38. No.41. P.7295-7298.

[9] U. Koch-Pomeranz, H.J. Hansen, H. Schmid. Photochemical cyclization of allylated anisole and $N$ alkylaniline derivatives. Helvetica Chimica Acta. 1975. Vol.58. P.178-182.

[10] I.B. Abdrakhmanov, A.G. Mustafin, G.A. Tolstikov, R.N. Fakhretdinov, U.M. Dzhemilev. Synthesis of indole and quinoline derivatives by intramolecular catalytic cyclization of allylanilines. Chemistry of Heterocyclic Compounds. 1986. No.3. P.325-327. (russian)

[11] R.R. Gataullin, M.F. Nasyrov, D.V. Shitikova, E.M. Vyrypaev, I.B. Abdrakhmanov. Synthesis of N(ortho- and para-alkenylphenyl) containing quinazolin-4-ones. Russian Journal of Applied Chemistry. 2001. Vol.74. No.6. P.963-965. (russian)

[12] R.R. Gataullin, I.S. Afonkin, A.A. Fatykhov, L.V. Spirikhin, E.V. Talvinskiy, I.B. Abdrakhmanov. A convenient way to obtain 3,1-benzoxazines from N-acyl-ortho-(alk-1-enyl) anilines. Russian Chemical Bulletin. 2001. No.4. P.633-638. (russian)

[13] R.R. Gataullin, I.S. Afonkin, A.A. Fatykhov, I.B. Abdrakhmanov. Synthesis of 3,1-benzoxazines from ortho-alkenylanilines. Chemistry of Heterocyclic Compounds. 2002. No.3. P.367-371. (russian)

[14] R.R. Gataullin, F.F. Minnigulov, A.A. Fatykhov, L.V. Spirikhin, I.B. Abdrakhmanov. Reactions of Nand C-alkenylanilines. III. Synthesis and cyclization of substituted 2-(1-methyl-2-butenyl) anilines. Russian Journal of Organic Chemistry. 2002. Vol.38. No.1. P.31-37. (russian)

[15] R.R. Gataullin, F.F. Minnigulov, A.R. Kudashev, R.A. Nurushev, I.B. Abdrakhmanov. Synthesis of alkenyl derivatives of difluoro-, trifluoro- and nitroanilines. Russian Journal of Applied Chemistry. 2002. Vol.75. No.1. P.95-97. (russian)

[16] I.B. Abdrakhmanov, V.M. Sharafutdinov, U.M. Dzhemilev, E.V. Talvinskiy, I.A. Sagitdinov, G.A. Tolstikov. Synthesis of $N$-substituted unsaturated amines. Russian Journal of Applied Chemistry. 1982. No.9. P.2121-2123. (russian)

[17] I.B. Abdrakhmanov, V.M. Sharafutdinov, I.A. Sagitdinov, G.A. Tolstikov. On the case of easy flow of the Claisen N-(1-methyl-2-butenyl) aniline rearrangement. Russian Journal of Organic Chemistry. 1979. Vol.15. No.12. P.2601. (russian)

[18] I.B. Abdrakhmanov, V.M. Sharafutdinov, N.G. Nigmatullin, I.A. Sagitdinov, G.A. Tolstikov. AminoClaisen rearrangement as a method of synthesis of C-substituted amines. Russian Journal of Organic Chemistry. 1982. Vol.18. No.7. P.1466-1471. (russian)

[19] I.B. Abdrakhmanov, V.M. Sharafutdinov, N.G. Nigmatullin, A.G. Mustafin, Z.N. Saraeva, G.A. Tolstikov. The Claisen rearrangement study in the series of N-allylanilines. Bulletin of the Academy of Sciences of the USSR. Division of Chemical Sciences. 1983. No.6. P.1273-1277. (russian)

[20] H. Albrecht, E.O. Duber, J. Epsztajn, R.M.K. Marcinkowski. Delocalization, conformation and basicity of anilines. Tetrahedron. 1984. Vol.40. No.7. P.1157-1165.

[21] V.M. Sharafutdinov. Amino-Claisen rearrangement in the interaction of secondary allyl chlorides with arylamines: Thesis for the degree of candidate of chemical sciences. Ufa: Institute of Chemistry, Bashkir Branch of the USSR Academy of Sciences. 1982. (russian)

[22] I.B. Abdrakhmanov, G.B. Shabaeva, G.A. Tolstikov. Rearrangement of N-(1-methyl-2-butenyl)-2methyl-6-ethylaniline to 2-methyl-6-ethyl-4-(1-methyl-2-butenyl) aniline. Bulletin of the Academy of Sciences of the USSR. Division of Chemical Sciences. 1984. No.10. P.2411. (russian)

[23] L.I. Bunina-Krivorukova, V.G. Yagodin, Kh.V. Balyan. On the rearrangement of crotyl and $\alpha-$ methylallyl ethers of p-cresol. Russian Journal of Organic Chemistry. 1972. Vol.8. No.1. P.140. (russian) 
[24] I.B. Abdrakhmanov, V.M. Sharafutdinov, I.A. Sagitdinov, A.G. Mustafin. Synthesis and cyclization of 2-(2-chloro-1-methyl-2-butenyl) anilines. Izvestiya vysshikh uchebnykh zavedenii. Khimiya $i$ khimicheskaya tekhnologiya. 1985. No.4. P.26-29. (russian)

[25] M. Schmid, H.-J. Hansen, H. Schmid. Zinkchloridkatalysierte, thermische Umlagerungen von $N$-Allylin C-Allyl-aniline, Ladungsinduzierte, aromatische Amino-Claisen-Umlagerungen. Helvetica Chimica Acta. 1973. Vol.56. P.105-124.

[26] S. Jolidon, H.-J. Hansen. Untersuchungen über aromatische Amino-Claisen-Umlagerungen. Helvetica Chimica Acta. 1977. Vol.60. P.978-1032.

[27] S. Jolidon, H.-J. Hansen. Mechanismus der photochemischen methanol-addition an 2-allylierte aniline. Helvetica Chimica Acta. 1979. Vol.62. P.2588-2612.

[28] I.B. Abdrakhmanov, V.M. Sharafutdinov, G.A. Tolstikov. Acid-catalyzed rearrangement of N-(1methyl-2-butenyl) aniline. Russian Journal of Organic Chemistry. 1984. Vol.20. No.3. P.620-622. (russian)

[29] I.B. Abdrakhmanov, I.M. Borisov, R.R. Ismagilov, N.G. Nigmatullin, R.N. Khusnitdinov, G.A. Tolstikov. Features of the mechanism of amino Claisen rearrangement. Russian Chemical Bulletin. 2013. No.1. P.83-87. (russian)

[30] T. Gilchrist, R. Storr. Organic reactions and orbital symmetry. Moscow: Mir. 1976. P. 263. (russian)

[31] I.B. Abdrakhmanov, N.G. Nigmatullin, B.G. Zykov, Z.N. Saraeva, O.A. Ponomarev, G.A. Tolstikov. Quantum-chemical investigation of the Claisen amino-rearrangement mechanism. Bulletin of the Academy of Sciences of the USSR. Division of Chemical Sciences. 1991. No.3. P.634-639. (russian) 